\title{
Drug use during pregnancy in Sweden - assessed by the Prescribed Drug Register and the Medical Birth Register
}

This article was published in the following Dove Press journal:

Clinical Epidemiology

28 January 2011

Number of times this article has been viewed

\section{Olof Stephansson \\ Fredrik Granath \\ Tobias Svensson \\ Bengt Haglund \\ Anders Ekbom \\ Helle Kieler \\ Clinical Epidemiology Unit and \\ Centre for Pharmacoepidemiology, \\ Department of Medicine, Karolinska \\ University Hospital and Institutet, \\ Stockholm, Sweden}

Correspondence: Olof Stephansson

Clinical Epidemiology Unit and Centre

for Pharmacoepidemiology, Department

of Medicine, Karolinska University

Hospital and Institutet,T2, Solna,

SE-17I 76 Stockholm, Sweden

Tel +46851779106

Fax +46851779304

Email olof.stephansson@ki.se
Purpose: The purpose of this research is to study drug use during pregnancy in Sweden and agreement between use according to antenatal medical records and dispensed drugs from a pharmacy database.

Patients and methods: From the Swedish Medical Birth Register (MBR), we established a population-based cohort of 102,995 women who gave birth in 2007. Using the unique personal registration number, information on dispensed drugs from the Prescribed Drug Register (PDR) was obtained prior to, during, and after the pregnancies and compared with MBR information on drug use from standardized antenatal medical records.

Results: According to the PDR, $57.6 \%$ of the 102,995 women filled a prescription with at least one drug during pregnancy and $50.9 \%$ during the lactating period (until 3 months after delivery). The most dispensed drugs during pregnancy were B-lactam antibacterials and penicillins. Agreement between drugs recorded in antenatal medical records and dispensed drugs was highest for drugs used for chronic conditions. The agreement was particularly high for thyroid therapy $(85.3 \%)$, anti-intestinal inflammatory drugs $(80.3 \%)$, antiepileptics (69.2\%), immunosuppressants (67.4\%), and insulin (63.8\%). Agreement for drugs used for occasional use was generally lower, ranging between $42.5 \%$ for antihistamines and $0.8 \%$ for gynecological anti-infectives.

Conclusions: A large proportion of women filled a prescription during pregnancy or the lactating period. Agreement between drug use in medical antenatal records and register information from a national pharmacy database was high for drugs used for chronic conditions but low for occasional use. For occasionally used drugs, medical record and register-based data may provide incomplete exposure information because of nonreporting or noncompliance.

Keywords: drug utilization, pregnancy, lactation, pharmacoepidemiology

\section{Introduction}

Most women use prescribed drugs during pregnancy according to studies from Europe and the United States. ${ }^{1-8}$ Use of drugs during pregnancy is complicated because of the limited knowledge with regard to beneficial and possible adverse effects for both the mother and the fetus as pregnant women are rarely included in drug trials.

Presumably noncompliance for prescribed drugs during pregnancy is prevalent, but as the information on drug use might differ depending on how it was obtained, knowledge about use during pregnancy is still relatively unknown. ${ }^{9,10}$ In a Danish study, Olesen et al compared dispensed drugs from a prescription database with information on intake obtained from telephone interviews with pregnant women. The results revealed that drugs used for chronic diseases during pregnancy were always reported to be used, 
which was not the case for local or short-term used drugs. ${ }^{9}$ However, women may report differently to health care personnel compared with an interviewer on the telephone, and the women who participated in the Danish study may have been more 'compliant' when compared to nonparticipating women. Hence, the results may not be generalized to pregnant women in a clinical setting. In Sweden, information on drugs used during pregnancy is recorded at first visit to antenatal care and throughout pregnancy within the standardized antenatal medical record. Since 1994, the information on drug use has been forwarded to the Swedish Medical Birth Register (MBR), and several studies have used the information in the MBR to assess possible adverse effects of drugs used during pregnancy despite the limited knowledge concerning data validity. ${ }^{11}$ The aims of the present study were to study prescribed dispensed drugs among pregnant and lactating women using information from the Swedish Prescribed Drug Register (PDR) and to compare this information with drug use reported in the standardized medical antenatal records and included in the MBR.

\section{Material and methods Study population}

We used the MBR to identify women with singleton births between January 1 and December 31, 2007. The MBR recorded 102,995 women during the study period, and by means of each individual's unique civil registration number (CPR), we linked data from this register with data from the $\mathrm{PDR}^{12}$ to identify prescribed dispensed drugs 3 months prior to pregnancy until 3 months after delivery. The CPR is assigned to all residents in Sweden at birth or immigration. ${ }^{13}$ The PDR contains information with unique patient identifiers for all prescriptions dispensed to the whole population of Sweden ( 9 million inhabitants). For prescribed drugs, the register includes data on dispensed item, substance, brand name, formulation, package size, dispensed amount, dosage, expenditure, and reimbursement. There is also information on date of prescribing and dispensing, as well as prescriber's profession and practice. All drugs are classified according to the World Health Organization Anatomical Therapeutic Chemical (ATC) classification. There is no information on over-the-counter (OTC) medications and for drugs used or administered in hospitals. ${ }^{12}$

The population-based MBR includes prospectively collected information, including demographic data, reproductive history, and complications during pregnancy, delivery, and the neonatal period among more than $98 \%$ of all births in Sweden. ${ }^{14}$ In the MBR, maternal characteristics are recorded in a standardized manner during a woman's first visit for antenatal care, which occurs during first the trimester in more than $95 \%$ of the pregnancies. Gestational age was primarily based on prenatal ultrasound estimation of last menstrual period (LMP) if present, and otherwise estimated on the recorded date of the first day of LMP. Ultrasound for determination of gestational length has been offered to all pregnant women in Sweden since $1990,95 \%$ of whom accept it. ${ }^{15}$

At first visit to antenatal care, the midwife records drugs used during pregnancy. This includes information on brand name, formulation, dosage, and gestational week of use. At each antenatal visit, the midwife and the attending doctor update information on drug use in the standardized record, including gestational week at start and end of use. The completeness of this information is not known. In the MBR, information on drug use is converted into ATC codes. Self-reported drug use during pregnancy includes prescribed drugs, OTC drugs, natural remedies, and homeopathics.

Dispensed drugs from PDR were described from 3 months prior to estimated LMP to 3 months postpartum for each woman. According to the date of birth and predicted time of LMP, each pregnancy was divided into five periods: a) prepregnancy (3 months before LMP), b) first trimester (0-13 weeks), c) second trimester (14-28 weeks), d) third trimester (29 to weeks until delivery), and $e$ ) lactation period (until 3 months postpartum). Agreement between dispensed drugs in the PDR and recorded drug use in MBR until first visit to antenatal care was calculated as predictive values with $95 \%$ confidence intervals $(95 \% \mathrm{CI})$, presented by ATC groups categorized into drugs used for chronic conditions and occasional use. Agreement of drug use was defined as the proportion of drugs dispensed according to PDR from 90 days before until date of first visit to antenatal care. The mean gestational age at first attendance was 86.7 days, which corresponds to gestational week 12 . For women who attended antenatal care later than 90 days from LMP, the time period was extended to include time from LMP to first visit to antenatal care. The 90-day period was chosen as prescriptions in Sweden are usually collected at 3-month intervals. Using this method, we obtained complete information on drugs used for both chronic conditions and occasional use.

We also analyzed the proportion of women with reported drug use by ATC category until first attendance at antenatal care in the MBR compared to drugs recorded in the PDR between 90 and 180 days before first attendance at antenatal care.

All analyses were conducted using SAS software, version 9.2 (SAS Institute, Inc, Cary, NC, USA). 
The study was approved (no. 2008/1182-31/4) by one of the regional ethical review boards in Stockholm, Sweden.

\section{Results}

A total of 102,995 women with singleton births was registered in the MBR during 2007. Among these women, $57.6 \%(\mathrm{n}=59,281)$ purchased at least one prescribed drug during pregnancy and $50.9 \%$ during the lactating period (until 3 months after delivery, Table 1). The most widely purchased drugs during preconception were antibacterials for systemic use (J01) followed by sex hormones (G03), NSAIDs (M01A), antidepressants (N06A), and drugs for the respiratory system (R). For most ATC categories, there was a decrease in the proportion of women who purchased at least one prescribed drug during pregnancy. More than half of all women $(n=52,425)$ collected at least one prescribed drug during the lactation period (Table 1).

Table 2 presents agreement between drug use recorded in the PDR from 90 days before until the first visit to antenatal care and drug use reported in MBR. In general, agreement was higher for drugs used for chronic conditions compared with drugs used more occasionally. Among chronic conditions, the best agreement (85.3\%) was found for thyroid therapy (H03) followed by anti-intestinal inflammatory (A07E), antiepileptic (N03), and immunosuppressant drugs (L04), and insulin (A10A). The best agreement for drugs used more occasionally was $42.5 \%$ for antihistamines (R06). Only 7 out of 840 with dispensed gynecological anti-infective drugs had their drugs reported in the MBR (Table 2).

Table 3 presents the number and proportion of women with reported drug use according to MBR, also registered in the PDR from 90 and from 180 days prior to first visit to antenatal care. Among 470 women who used insulin according to antenatal medical records, $376(80.0 \%)$ had filled a prescription within 90 days before first visit to antenatal care and 434 (92.3\%) within 180 days before the visit (Table 3). More than 7 out of 10 women who used antiepileptics (N03), thyroid therapy (H03), antipsychotics (N05A), immunosuppressants (N06A), or antidepressants (N06A) were registered in the PDR within 90 days before their first visit to antenatal care. The lowest agreement between drug use reported in the antenatal medical records and information from the PDR was found for ophthalmologicals (S01) and antifungals for dermatological use (D01A) (Table 3).

\section{Discussion}

In the present study, we found that use of prescribed drugs during pregnancy is prevalent in Sweden with a large variation during pregnancy and lactation periods. The agreement between drug use registered in the MBR and filled prescriptions recorded in the PDR was high for drugs used for chronic conditions, but not for drugs used more occasionally. As the information in the MBR is based on self-reported drug use and recorded in the antenatal medical records and the information in the PDR reflects filled prescriptions, the low agreement for occasionally used drugs between the two registers may reflect both nonreporting and noncompliance. Consequently, for occasionally used drugs, neither of the registers is more advantageous than the other as the only source of information for drug exposure, and for future studies, presumably the combined information will be the best estimate.

In the study by Olesen et al based on telephone interviews during pregnancy, agreement was high for drugs used for chronic diseases like beta-blockers, insulin, and thyroid therapy, which is similar to our findings. ${ }^{9}$ Previous studies have found that low socioeconomic status is associated with use of prescription medication during pregnancy, and as individuals with low socioeconomic status may be less prone to participate in surveys, the results from the Danish study may not be applicable to pregnant women in general or women with low socioeconomic status in particular., ${ }^{416}$

When information on drug use is obtained from interviews in surveys or in the clinical setting, the type of drug might influence recall accuracy. For drugs used more occasionally, there is a possibility that a woman fails to report drug use or prefers not reporting it to the midwife because she considers it to be of no importance or because she might fear that reporting the drug intake may complicate her pregnancy. A Dutch study concluded that interview data will outweigh data from pharmacy records for self-medication and compliance, whereas pharmacy records will give better information in case of long recall periods and in patients with multiple and repeated drug use. ${ }^{10}$

An additional and complicating aspect when estimating drug use from filled prescriptions is the time that might pass between drug purchase and medication start. Generally, in Sweden, a prescription will cover a period of 90 days. However, when we expanded the time period to include prescriptions filled up to 180 days prior to the first antenatal care visit, we found a better agreement between the information obtained from self-reported use and recorded in the MBR and the information on purchased drugs from the PDR, indicating a delay in starting a medication or using a lower dose than prescribed. We are not able to address whether this delay or altered dosing is the normal pattern of use of 
Table I Number and proportion of women with dispensed drugs from 3 months prior to pregnancy until 3 months postpartum according to the Prescribed Drug Register among 102,995 women delivered in Sweden, 2007

\begin{tabular}{|c|c|c|c|c|c|c|c|c|c|c|}
\hline \multirow[t]{2}{*}{ ATC category } & \multicolumn{2}{|c|}{$\begin{array}{l}\text { Until } 3 \text { months } \\
\text { before pregnancy }\end{array}$} & \multicolumn{2}{|c|}{$\begin{array}{l}\text { First } \\
\text { trimester }\end{array}$} & \multicolumn{2}{|c|}{$\begin{array}{l}\text { Second } \\
\text { trimester }\end{array}$} & \multicolumn{2}{|c|}{$\begin{array}{l}\text { Third } \\
\text { trimester }\end{array}$} & \multicolumn{2}{|c|}{$\begin{array}{l}\text { Lactation period } \\
0-3 \text { months }\end{array}$} \\
\hline & $\mathbf{N}$ & $\%$ & $\mathbf{N}$ & $\%$ & $\mathbf{N}$ & $\%$ & $\mathbf{N}$ & $\%$ & $\mathbf{N}$ & $\%$ \\
\hline Alimentary tract and metabolism (A) & 4510 & 4.38 & 5305 & 5.15 & 4324 & 4.20 & 4099 & 3.98 & 4695 & 4.56 \\
\hline Antacids and drugs for peptic ulcer (A02) & 1524 & 1.48 & 1713 & 1.66 & 1220 & 1.18 & 1213 & 1.18 & 668 & 0.65 \\
\hline Propulsive (A03) & 286 & 0.28 & 938 & 0.91 & 389 & 0.38 & 123 & 0.12 & 202 & 0.20 \\
\hline Anti-intestinal inflammatory drugs (A07E) & 304 & 0.30 & 291 & 0.28 & 284 & 0.28 & 265 & 0.26 & 242 & 0.23 \\
\hline Insulin (AIOA) & 392 & 0.38 & 527 & 0.51 & 654 & 0.63 & 884 & 0.86 & 392 & 0.38 \\
\hline Drugs for diabetes (AIOB) & 215 & 0.21 & 121 & 0.12 & 14 & 0.01 & 8 & 0.01 & 28 & 0.03 \\
\hline Blood and blood-forming organs (B) & 2008 & 1.95 & 3147 & 3.06 & 3457 & 3.36 & 3213 & 3.12 & 2974 & 2.89 \\
\hline Antithrombotic agents (BOI) & 197 & 0.19 & 1016 & 0.99 & 1215 & 1.18 & 1024 & 0.99 & 1963 & 1.91 \\
\hline Iron (B03A) & 412 & 0.40 & 583 & 0.57 & 925 & 0.90 & 799 & 0.78 & 448 & 0.43 \\
\hline Vitamin $B_{12}$ and folic acid (B03B) & 1312 & 1.27 & 1560 & 1.51 & 1446 & 1.40 & 1467 & 1.42 & 503 & 0.49 \\
\hline Cardiovascular system (C) & 1106 & 1.07 & 982 & 0.95 & 1052 & 1.02 & 1612 & 1.57 & 3153 & 3.06 \\
\hline Diuretic (C03) & 131 & 0.13 & 99 & 0.10 & 53 & 0.05 & 69 & 0.07 & 138 & 0.13 \\
\hline Beta-blockers (C07) & 448 & 0.43 & 448 & 0.43 & 407 & 0.40 & 751 & 0.73 & 1198 & 1.16 \\
\hline Calcium blockers (C08) & 54 & 0.05 & 35 & 0.03 & 51 & 0.05 & 100 & 0.10 & 178 & 0.17 \\
\hline $\begin{array}{l}\text { Agents acting on the renin-angiotensin } \\
\text { system (C09) }\end{array}$ & 92 & 0.09 & 44 & 0.04 & 3 & 0.003 & 5 & 0.005 & 132 & 0.13 \\
\hline Dermatologicals (D) & 3789 & 3.68 & 3452 & 3.35 & 3246 & 3.15 & 2498 & 2.43 & 4428 & 4.30 \\
\hline Antifungals for dermatological use (D0IA) & 749 & 0.73 & 815 & 0.79 & 799 & 0.78 & 555 & 0.54 & 2065 & 2.00 \\
\hline $\begin{array}{l}\text { Antibiotics and chemotherapy for } \\
\text { dermatological use (D06) }\end{array}$ & 298 & 0.29 & 224 & 0.22 & 176 & 0.17 & 137 & 0.13 & 298 & 0.29 \\
\hline Dermal corticosteroids (D07) & 1808 & 1.76 & 1540 & 1.50 & $|52|$ & 1.48 & 1099 & 1.07 & 1388 & 1.35 \\
\hline Antiacne preparations (DI0) & 531 & 0.52 & 428 & 0.42 & 265 & 0.26 & 137 & 0.13 & 152 & 0.15 \\
\hline Genitourinary system and sex hormones $(G)$ & 10,920 & 10.60 & 5624 & 5.46 & 1488 & 1.44 & 1012 & 0.98 & 24,365 & 23.66 \\
\hline Gynecological anti-infectives (G0I) & 623 & 0.60 & 1038 & 1.01 & $129 \mid$ & 1.25 & 902 & 0.88 & 323 & 0.31 \\
\hline Other gynecologicals (G02) & 610 & 0.59 & 137 & 0.13 & 10 & 0.01 & 13 & 0.01 & 2103 & 2.04 \\
\hline Sex hormones (G03) & 9846 & 9.56 & 4509 & 4.38 & 152 & 0.15 & 63 & 0.06 & 22,569 & 21.91 \\
\hline Systemic hormonal preparations $(H)$ & 3666 & 3.56 & 3047 & 2.96 & 2758 & 2.68 & 2515 & 2.44 & 6015 & 5.84 \\
\hline Corticosteroids for systemic use ( $\mathrm{H} 02)$ & 907 & 0.88 & 585 & 0.57 & 394 & 0.38 & 315 & 0.31 & 631 & 0.61 \\
\hline Thyroid therapy $(\mathrm{H} 03)$ & 1742 & 1.69 & 2102 & 2.04 & 2349 & 2.28 & 2187 & 2.12 & 1867 & 1.81 \\
\hline Anti-infectives for systemic use (J) & 11,622 & 11.28 & 10,835 & 10.52 & 11,492 & 11.16 & 10,506 & 10.20 & 14,897 & 14.46 \\
\hline Antibacterials for systemic use (J0I) & 10,015 & 9.72 & 10,012 & 9.72 & ||$, 08 \mid$ & 10.76 & 9720 & 9.44 & 14,183 & 13.77 \\
\hline Tetracyclines (J0|A) & 1549 & 1.50 & 674 & 0.65 & 75 & 0.07 & 18 & 0.02 & 475 & 0.46 \\
\hline B-lactam antibacterials and penicillins $(\mathrm{J} \mid \mathrm{C})$ & 5867 & 5.70 & 6664 & 6.47 & 7810 & 7.58 & 6496 & 6.31 & 9123 & 8.86 \\
\hline Other B-lactams (J0ID) & 735 & 0.71 & 982 & 0.95 & 1442 & 1.40 & 1368 & 1.33 & 3983 & 3.87 \\
\hline Sulfonamides and trimethoprim (JOIE) & 903 & 0.88 & 376 & 0.37 & 86 & 0.08 & 99 & 0.10 & 827 & 0.80 \\
\hline $\begin{array}{l}\text { Macrolides, lincosamides, and } \\
\text { streptogramins (JOIF) }\end{array}$ & 771 & 0.75 & 414 & 0.40 & 425 & 0.41 & 388 & 0.38 & 964 & 0.94 \\
\hline Quinolones (J0IM) & 812 & 0.79 & 310 & 0.30 & 34 & 0.03 & 27 & 0.03 & 197 & 0.19 \\
\hline Other antibacterials (JOIX) & 546 & 0.53 & 1624 & 1.58 & 2515 & 2.44 & 2324 & 2.26 & 380 & 0.37 \\
\hline Antimycotics for systemic use (J02) & 1160 & 1.13 & 503 & 0.49 & 182 & 0.18 & 186 & 0.18 & 818 & 0.79 \\
\hline Antiviral therapy (J05A) & 627 & 0.61 & 375 & 0.36 & 222 & 0.22 & 720 & 0.70 & 278 & 0.27 \\
\hline $\begin{array}{l}\text { Antineoplastic and immunomodulating } \\
\text { agents (L) }\end{array}$ & 1709 & 1.66 & 531 & 0.52 & 98 & 0.10 & 88 & 0.09 & 149 & 0.14 \\
\hline Immunosuppressant (L04) & 135 & 0.13 & 109 & 0.11 & 86 & 0.08 & 78 & 0.08 & 117 & 0.11 \\
\hline Musculoskeletal system (M) & 3784 & 3.67 & 1522 & 1.48 & 488 & 0.47 & 238 & 0.23 & 7408 & 7.19 \\
\hline NSAID (MOIA) & 3520 & 3.42 & 1315 & 1.28 & 350 & 0.34 & 163 & 0.16 & 7272 & 7.06 \\
\hline Muscle relaxants (M03) & 251 & 0.24 & 126 & 0.12 & 99 & 0.10 & 49 & 0.05 & 58 & 0.06 \\
\hline Nervous system (N) & 7494 & 7.28 & 6086 & 5.91 & 4849 & 4.71 & 4464 & 4.33 & 8071 & 7.84 \\
\hline Opioids (N02A) & $|79|$ & 1.74 & $|46|$ & 1.42 & 1754 & 1.70 & 1919 & 1.86 & 3362 & 3.26 \\
\hline Analgetics (N02B) & $|55|$ & 1.51 & 1312 & 1.27 & 1289 & 1.25 & 1132 & 1.10 & 3233 & 3.14 \\
\hline Antimigraine (N02C) & 825 & 0.80 & 521 & 0.51 & 260 & 0.25 & 149 & 0.14 & 209 & 0.20 \\
\hline
\end{tabular}


Table I (Continued)

\begin{tabular}{|c|c|c|c|c|c|c|c|c|c|c|}
\hline \multirow[t]{2}{*}{ ATC category } & \multicolumn{2}{|c|}{$\begin{array}{l}\text { Until } 3 \text { months } \\
\text { before pregnancy }\end{array}$} & \multicolumn{2}{|c|}{$\begin{array}{l}\text { First } \\
\text { trimester }\end{array}$} & \multicolumn{2}{|c|}{$\begin{array}{l}\text { Second } \\
\text { trimester }\end{array}$} & \multicolumn{2}{|c|}{$\begin{array}{l}\text { Third } \\
\text { trimester }\end{array}$} & \multicolumn{2}{|c|}{$\begin{array}{l}\text { Lactation period } \\
0-3 \text { months }\end{array}$} \\
\hline & $\mathbf{N}$ & $\%$ & $\mathbf{N}$ & $\%$ & $\mathbf{N}$ & $\%$ & $\mathbf{N}$ & $\%$ & $\mathbf{N}$ & $\%$ \\
\hline Antiepileptics (N03) & 337 & 0.33 & 308 & 0.30 & 261 & 0.25 & 244 & 0.24 & 307 & 0.30 \\
\hline Antipsychotics (N05A) & 194 & 0.19 & 677 & 0.66 & 189 & 0.18 & 64 & 0.06 & 114 & 0.11 \\
\hline Sedatives (N05B) & 1001 & 0.97 & 569 & 0.55 & 224 & 0.22 & 160 & 0.16 & 578 & 0.56 \\
\hline Hypnotics (N05C) & 1193 & 1.16 & 764 & 0.74 & 498 & 0.48 & 555 & 0.54 & 556 & 0.54 \\
\hline Antidepressants (N06A) & 3102 & 3.01 & 2062 & 2.00 & 1257 & 1.22 & 1029 & 1.00 & 1653 & 1.60 \\
\hline $\begin{array}{l}\text { Antiparasitic products, insecticides } \\
\text { and repellents }(P)\end{array}$ & 1223 & 1.19 & 472 & 0.46 & 238 & 0.23 & 158 & 0.15 & 2690 & 2.61 \\
\hline Respiratory system (R) & 7761 & 7.54 & 13,050 & 12.67 & $|2,2| 4$ & 11.86 & 10,747 & 10.43 & 5450 & 5.29 \\
\hline Nasal preparations (ROI) & 2936 & 2.85 & 2930 & 2.84 & 4081 & 3.96 & 3369 & 3.27 & 1453 & $1.4 \mathrm{I}$ \\
\hline Antiasthmatics (R03) & 2226 & 2.16 & 2294 & 2.23 & $27 I I$ & 2.63 & 2524 & 2.45 & 1556 & $1.5 \mathrm{I}$ \\
\hline Cough and cold preparations (R05) & 2378 & 2.31 & 2599 & 2.52 & 3481 & 3.38 & 3030 & 2.94 & 1470 & 1.43 \\
\hline Antihistamines (R06) & 2316 & 2.25 & 7727 & 7.50 & 4721 & 4.58 & 3868 & 3.76 & 2011 & 1.95 \\
\hline Sensory organs (S) & 2340 & 2.27 & 2011 & 1.95 & 1895 & 1.84 & 1508 & 1.46 & 1986 & 1.93 \\
\hline Ophthalmologicals (SOI) & 1790 & $\mathrm{I} .74$ & 1513 & 1.47 & 1452 & $1.4 \mathrm{I}$ & 1157 & 1.12 & 1533 & 1.49 \\
\hline Total & 37,277 & 36.19 & 36,167 & 35.12 & 32,002 & 31.07 & 29,572 & 28.71 & 52,267 & 50.75 \\
\hline
\end{tabular}

Abbreviations: ATC, Anatomical Therapeutic Chemical; NSAID, nonsteroidal anti-inflammatory drug.

prescribed drugs among women in reproductive age or if it was the pregnancy per se that influenced drug use.

Drug use during pregnancy is complicated by the potential risk for both mother and fetus. For women with chronic inflammatory disease like rheumatoid arthritis and inflammatory bowel disease, use of medications like methotrexate is clearly teratogenic, whereas there is a lack of knowledge concerning the safety of TNF-alpha-blockers during pregnancy. ${ }^{17} \mathrm{We}$ observed that corticosteroids for systemic use and immunosuppressant drugs were dispensed less during pregnancy compared to the 3-month period before pregnancy. As knowledge concerning adverse fetal effects of these drugs in humans is limited and serious adverse effects have been reported in animal studies, the precaution of reducing or avoiding systemic anti-inflammatory medication during pregnancy might be wise. ${ }^{18-20}$ On the other hand, unless pregnancy in itself reduces disease activity, stopping or reducing medication might increase risk of flares and worsening of the disease, which may also affect the fetus adversely. Agreement between self-reported and dispensed drugs was high for immunosuppressant therapy, whereas this was not found for systemic corticosteroid use. For thyroid therapy, on the other hand, use increased during pregnancy, and there was good agreement between self-reporting and expenditure data. These findings are in line with drug use during pregnancy in Denmark, with agreements of $100 \%$ and $20 \%$ for thyroid drugs and systemic corticosteroids, respectively. ${ }^{9}$

For studies on congenital abnormalities (CA), time of exposure is of importance because the period of teratogenesis may be quite short. There is a risk that studies based on linkage with prescription registers will be uncertain. This is less important for chronically used drugs compared with occasionally used drugs like antibiotics and sedatives. ${ }^{21}$ In addition, a teratogen does not uniformly increase the rates of all CA, but rather tends to increase rates of selected CA, which further emphasizes valid drug exposure information. ${ }^{22}$ Our finding of a low agreement between self-reported drug used as recorded in the MBR and purchased drugs recorded in the PDR for occasionally used drugs emphasizes the difficulties in using such information when studying these drugs in association with rare outcomes such as CA. ${ }^{23,24}$

Antibiotics were the most dispensed prescribed drug during pregnancy, and the proportion of women filling prescriptions with antibiotics increased further during the lactating period reaching almost $14 \%$. The most prescribed antibiotic drugs were B-lactam antibacterials and penicillins, and we observed strong decline in dispensed antibiotics not recommended during pregnancy. Similar findings were reported in a Norwegian ${ }^{5}$ and a German ${ }^{25}$ study. Among women with a dispensed antibiotic drug from 90 days before first visit to antenatal care, only $20 \%$ reported this intake according to the medical records. Conversely, among women who reported use of antibiotics, $83 \%$ were dispensed according to the register within 90 days from first attendance at antenatal care.

The use of drugs for the nervous system decreased during pregnancy except for antipsychotics (N05A), where there was a strong increase in dispensed drugs during first trimester. Similar findings were reported from Norway. ${ }^{5}$ The safety 
Table 2 Number of women with dispensed prescribed drugs according to the PDR from 90 days before first visit to antenatal care,' number of women who reported drug use according to the MBR, and the predictive value of reporting drug use in MBR after a dispensed prescription in Sweden, 2007

\begin{tabular}{|c|c|c|c|c|}
\hline \multirow[t]{2}{*}{ ATC category } & \multirow{2}{*}{$\frac{\text { PDR }}{N}$} & \multirow{2}{*}{$\frac{\text { PDR and } M B R}{N}$} & \multicolumn{2}{|c|}{ Agreement } \\
\hline & & & $\%$ & $95 \% \mathrm{Cl}$ \\
\hline \multicolumn{5}{|l|}{ Chronic conditions } \\
\hline Thyroid therapy $(\mathrm{H03})$ & 1776 & 1515 & 85.3 & $(83.6-86.9)$ \\
\hline Anti-intestinal inflammatory drugs (A07E) & 274 & 220 & 80.3 & $(75.1-84.8)$ \\
\hline Antiepileptics (N03) & 302 & 209 & 69.2 & $(63.7-74.4)$ \\
\hline Immunosuppressant (L04) & 98 & 66 & 67.4 & $(57.1-76.5)$ \\
\hline Insulin (AIOA) & 589 & 376 & 63.8 & $(59.8-67.7)$ \\
\hline Beta-blockers (C07) & 407 & 259 & 63.6 & $(58.7-68.3)$ \\
\hline Antidepressants (N06A) & 2225 & $|33|$ & 59.8 & $(57.7-6 \mid .9)$ \\
\hline Antiasthmatics (R03) & 2123 & 1226 & 57.8 & $(55.6-59.9)$ \\
\hline Antipsychotics (N05A) & 479 & 232 & 48.4 & $(43.9-53.0)$ \\
\hline Diuretic (C03) & 104 & 44 & 42.3 & $(32.7-52.4)$ \\
\hline Calcium blockers (C08) & 39 & 15 & 38.5 & $(23.4-55.4)$ \\
\hline Analgetics (N02B) & $|36|$ & 318 & 23.4 & $(21.1-25.7)$ \\
\hline Opioids (N02A) & 1460 & 314 & 21.5 & $(19.4-23.7)$ \\
\hline Antimigraine (N02C) & 570 & 122 & 21.4 & $(18.1-25.0)$ \\
\hline Corticosteroids for systemic use ( $\mathrm{H} 02)$ & 652 & 79 & I2.1 & $(9.7-14.9)$ \\
\hline NSAID (MOI) & 1843 & 172 & 9.3 & $(8.0-10.8)$ \\
\hline \multicolumn{5}{|l|}{ Occasional use } \\
\hline Antihistamines (R06) & 5625 & 2392 & 42.5 & $(41.2-43.8)$ \\
\hline Propulsive (A03) & 706 & 215 & 30.5 & $(27.1-34.0)$ \\
\hline Antacids and drugs for peptic ulcer (A02) & 1552 & 436 & 28.1 & $(25.9-30.4)$ \\
\hline Hypnotics (N05C) & 829 & 205 & 24.7 & $(21.8-27.8)$ \\
\hline Antibacterials for systemic use (J0I) & 9493 & 1946 & 20.5 & $(19.7-21.3)$ \\
\hline Sedatives (N05B) & 658 & 132 & 20.1 & $(17.1-23.3)$ \\
\hline Antiviral therapy (J05A) & 400 & 74 & 18.5 & $(14.8-22.7)$ \\
\hline Nasal preparations (ROI) & 2733 & 441 & 16.1 & $(14.8-17.6)$ \\
\hline Sex hormones (G03) & 5096 & 523 & 10.3 & $(9.4-11.1)$ \\
\hline Ophthalmologicals (SOI) & 1522 & 95 & 6.2 & $(5.1-7.6)$ \\
\hline Antimycotics for systemic use (J02) & 671 & 38 & 5.7 & $(4.0-7.7)$ \\
\hline Dermal corticosteroids (D07) & 1515 & 81 & 5.4 & $(4.3-6.6)$ \\
\hline Antifungals for dermatological use ( $\mathrm{D} 0 \mid \mathrm{A})$ & 753 & 19 & 2.5 & $(1.5-3.9)$ \\
\hline Gynecological anti-infectives (G0I) & 840 & 7 & 0.8 & $(0.3-1.7)$ \\
\hline
\end{tabular}

Notes: 'For women who attended antenatal care later than 90 days from last menstrual period, the time period was extended to include time from last menstrual period to first visit to antenatal care.

Abbreviations: ATC, Anatomical Therapeutic Chemical; NSAID, nonsteroidal anti-inflammatory drug; Cl, confidence interval; PDR, Prescribed Drug Register; MBR, Medical Birth Register.

of antipsychotics during pregnancy remains unclear, but women who discontinue treatment during pregnancy have an increased risk of relapse. ${ }^{26}$ Antipsychotic use during pregnancy has been associated with increased risk of $\mathrm{CA}^{27}$ and preterm delivery, whereas risks of low birth weight and smallfor-gestational-age birth were not influenced by antipsychotic use in a large Taiwan study. ${ }^{26}$

A major strength of the present study is the use of a population-based cohort comprising almost all deliveries in Sweden in 2007. Data from the PDR contains all expenditures of prescribed drugs in pharmacies in Sweden. Hence, we have an almost complete coverage of prescribed drugs dispensed during pregnancy. Information in the MBR on drug use and maternal characteristics is prospectively reported in early pregnancy, and consequently, the risk of recall bias is limited.

A limitation of this study is the lack of information on drugs used in hospitals. Hence, there may be an underreporting of drugs administrated by infusion and drugs for chronic psychiatric and rheumatic disease. However, this would most likely influence the findings for chronic conditions and not for occasional use. Furthermore, we do not have any information in the PDR on OTC drugs, and the low compliance between self-reported and register information on, for example, NSAID and analgetics may stem from OTC drugs or from drugs dispensed by the partner or other bound to share medication. In the present study, we included only women with a delivery from gestational week 22 and onward, and consequently, we were not 
Table 3 Number and proportion of women who reported drug use according to the MBR and dispensed prescribed drugs in the PDR 90 and 180 days before first visit to antenatal care in Sweden, 2007

\begin{tabular}{|c|c|c|c|c|c|c|c|}
\hline \multirow[t]{2}{*}{ ATC category } & \multirow{2}{*}{$\begin{array}{l}\text { MBR } \\
\bar{N}\end{array}$} & \multirow{2}{*}{$\begin{array}{l}\text { PDR and } \\
\text { MBR } 90 \text { days } \\
\mathbf{N}\end{array}$} & \multicolumn{2}{|c|}{$\begin{array}{l}\text { Proportion in PDR } \\
\text { within } 90 \text { days }\end{array}$} & \multirow{2}{*}{$\begin{array}{l}\text { PDR and } \\
\text { MBR I80 days } \\
N\end{array}$} & \multicolumn{2}{|c|}{$\begin{array}{l}\text { Proportion in PDR } \\
\text { within I } 80 \text { days }\end{array}$} \\
\hline & & & $\%$ & $95 \% \mathrm{Cl}$ & & $\%$ & $95 \% \mathrm{Cl}$ \\
\hline \multicolumn{8}{|l|}{ Chronic conditions } \\
\hline Insulin (AIOA) & 470 & 376 & 80.0 & $(76.1-83.5)$ & 434 & 92.3 & $(89.6-94.6)$ \\
\hline Antiepileptics (N03) & 269 & 209 & 77.7 & $(72.2-82.6)$ & 238 & 88.5 & $(84.0-92.0)$ \\
\hline Thyroid therapy $(\mathrm{H} 03)$ & 1919 & 1515 & 78.9 & (77.I-80.8) & $|75|$ & 91.3 & $(90.0-92.5)$ \\
\hline Antipsychotics (N05A) & 303 & 232 & 76.6 & (7I.4-8I.2) & 246 & 81.2 & $(76.3-85.4)$ \\
\hline Immunosuppressant (L04) & 91 & 66 & 72.5 & $(62.2-81.4)$ & 81 & 89.0 & $(80.7-94.6)$ \\
\hline Antidepressants (N06A) & $|86|$ & $|33|$ & 71.5 & $(69.4-73.6)$ & 1640 & 88.1 & $(86.6-89.6)$ \\
\hline Beta-blockers (C07) & 373 & 259 & 69.4 & $(64.5-74.1)$ & 298 & 79.9 & $(75.5-83.8)$ \\
\hline Diuretic $(\mathrm{CO})$ & 66 & 44 & 66.7 & $(54.0-77.8)$ & 55 & 83.3 & (72.I-9I.4) \\
\hline Antimigraine (N02C) & 200 & 122 & 61.0 & $(53.9-67.8)$ & 150 & 75.0 & $(68.4-80.8)$ \\
\hline Calcium blockers (C08) & 26 & 15 & 57.7 & $(36.9-76.6)$ & 20 & 76.9 & $(56.4-91.0)$ \\
\hline $\begin{array}{l}\text { Anti-intestinal inflammatory } \\
\text { drugs (A07E) }\end{array}$ & 391 & 220 & 56.3 & $(5|.2-6| .2)$ & 265 & 67.8 & $(62.9-72.4)$ \\
\hline Opioids (N02A) & 576 & 314 & 54.5 & $(50.3-58.6)$ & 364 & 63.2 & $(59.1-67.1)$ \\
\hline Antiasthmatics (R03) & 2977 & 1226 & 41.2 & $(39.4-43.0)$ & 1612 & 54.2 & $(52.3-56.0)$ \\
\hline Corticosteroids for systemic use ( $\mathrm{H} 02)$ & 260 & 79 & 30.4 & $(24.9-36.4)$ & 98 & 37.7 & $(31.8-43.9)$ \\
\hline NSAID (M0I) & 1254 & 172 & 13.7 & $(|I .9-| 5.7)$ & 244 & 19.5 & $(|7.3-2| .8)$ \\
\hline Analgetics (N02B) & 6669 & 318 & 4.8 & $(4.3-5.3)$ & 442 & 6.6 & $(6.0-7.3)$ \\
\hline \multicolumn{8}{|l|}{ Occasional use } \\
\hline Antibacterials for systemic use (J0I) & 2342 & 1946 & 83.1 & $(81.5-84.6)$ & 1989 & 84.9 & $(83.4-86.4)$ \\
\hline Propulsive (A03) & 292 & 215 & 73.6 & $(68.2-78.6)$ & 226 & 77.4 & $(72.2-82.1)$ \\
\hline Antiviral therapy (J05A) & 112 & 74 & 66.1 & $(56.5-74.8)$ & 84 & 75.0 & $(65.9-82.7)$ \\
\hline Sex hormones (G03) & 819 & 523 & 63.9 & $(60.5-67.2)$ & 605 & 73.9 & $(70.7-76.9)$ \\
\hline Sedatives (N05B) & 213 & 132 & 62.0 & $(55.1-68.5)$ & 160 & 75.1 & $(68.8-80.8)$ \\
\hline Hypnotics (N05C) & 333 & 205 & 61.6 & $(56.1-66.8)$ & 240 & 72.1 & $(66.9-76.8)$ \\
\hline Antimycotics for systemic use (J02) & 61 & 38 & 62.3 & $(50.0-74.4)$ & 46 & 75.4 & $(62.7-85.5)$ \\
\hline Gynecological anti-infectives (G0I) & 17 & 7 & 41.2 & $(18.4-67.1)$ & 7 & 41.2 & $(18.4-67.1)$ \\
\hline Antihistamines (R06) & 6007 & 2392 & 39.8 & $(38.6-4 I .1)$ & 2564 & 42.7 & $(4 I .4-43.9)$ \\
\hline Dermal corticosteroids (D07) & 220 & 81 & 36.8 & $(30.4-43.6)$ & 113 & 51.4 & $(44.6-58.1)$ \\
\hline Nasal preparations (ROI) & 1257 & 441 & 35.1 & $(32.4-37.8)$ & 537 & 42.7 & $(40.0-45.5)$ \\
\hline $\begin{array}{l}\text { Antacids and drugs for } \\
\text { peptic ulcer (A02) }\end{array}$ & 1332 & 436 & 32.7 & $(30.2-35.3)$ & 515 & 38.7 & $(36.0-41.3)$ \\
\hline Ophthalmologicals (SOI) & 295 & 95 & 32.2 & $(26.9-37.9)$ & 105 & 35.6 & $(30.1-4 I .3)$ \\
\hline $\begin{array}{l}\text { Antifungals for dermatological } \\
\text { use (DOIA) }\end{array}$ & 129 & 19 & 14.7 & $(9.1-22.0)$ & 23 & 17.8 & $(11.7-25.5)$ \\
\hline
\end{tabular}

Abbreviations: ATC, Anatomical Therapeutic Chemical; NSAID, nonsteroidal anti-inflammatory drug; PDR, Prescribed Drug Register; MBR, Medical Birth Register.

able to study drug use in relation to miscarriage or terminations of pregnancies because of suspected malformations or drug use in early pregnancy. In addition, we chose to include only women giving birth to singletons, as pregnancies with more than one fetus, in general, are under closer surveillance with higher risks of drug treatment and women giving birth to more than one infant will be less prone to breast-feed, which might affect their drug intake. Accordingly, the results from this study reflect only women giving birth to singletons.

\section{Conclusion}

In conclusion, we found that a large proportion of women in Sweden collected a dispensed drug during pregnancy and the lactating period. Agreement between drug use in medical records at antenatal care and register information was high for drugs used for chronic conditions but low for occasional use. Consequently, for occasionally used drugs, both medical record and register data may provide incomplete exposure information because of nonreporting or noncompliance.

\section{Acknowledgments}

Olof Stephansson was supported by a postdoc scholarship from the Swedish Society of Medicine.

\section{Disclosure}

The authors report no conflicts of interest in this work. 


\section{References}

1. Egen-Lappe V, Hasford J. Drug prescription in pregnancy: analysis of a large statutory sickness fund population. Eur J Clin Pharmacol. 2004;60(9):659-666.

2. Olesen C, Steffensen FH, Nielsen GL, de Jong-van den Berg L, Olsen J, Sørensen HT. Drug use in first pregnancy and lactation: a populationbased survey among Danish women. The EUROMAP group. Eur $J$ Clin Pharmacol. 1999;55(2):139-144.

3. Malm H, Martikainen J, Klaukka T, Neuvonen PJ; Finnish Register-Based Study. Prescription drugs during pregnancy and lactation-a Finnish register-based study. Eur J Clin Pharmacol. 2003; 59(2):127-133.

4. Riley EH, Fuentes-Afflick E, Jackson RA, et al. Correlates of prescription drug use during pregnancy. $J$ Womens Health (Larchmt). 2005; 14(5):401-409.

5. Engeland A, Bramness JG, Daltveit AK, Rønning M, Skurtveit S, Furu K. Prescription drug use among fathers and mothers before and during pregnancy. A population-based cohort study of 106,000 pregnancies in Norway 2004-2006. Br J Clin Pharmacol. 2008;65(5):653-660.

6. Lacroix I, Hurault C, Sarramon MF, et al. Prescription of drugs during pregnancy: a study using EFEMERIS, the new French database. Eur J Clin Pharmacol. 2009;65(8):839-846.

7. Andrade SE, Gurwitz JH, Davis RL, et al. Prescription drug use in pregnancy. Am J Obstet Gynecol. 2004;191(2):398-407.

8. Lee E, Maneno MK, Smith L, et al. National patterns of medication use during pregnancy. Pharmacoepidemiol Drug Saf. 2006; 15(8):537-545.

9. Olesen C, Søndergaard C, Thrane N, Nielsen GL, de Jong-van den Berg L, Olsen J; EuroMAP Group. Do pregnant women report use of dispensed medications? Epidemiology. 2001;12(5):497-501.

10. De Jong-van den Berg LT, Waardenburg CM, Haaijer-Ruskamp FM, Dukes MN, Wesseling H. Drug use in pregnancy: a comparative appraisal of data collecting methods. Eur J Clin Pharmacol. 1993; 45(1):9-14.

11. Centre for Epidemiology, National Board of Health and Welfare. The Swedish Medical Birth Register: A Summary of Content and Quality. Stockholm (Sweden): Centre for Epidemiology, National Board of Health and Welfare; 2003. (article no. 2003-112-3).

12. Wettermark B, Hammar N, Fored CM, et al. The new Swedish Prescribed Drug Register-opportunities for pharmacoepidemiological research and experience from the first six months. Pharmacoepidemiol Drug Saf. 2007;16(7):726-735.
13. Ludvigsson JF, Otterblad-Olausson P, Pettersson BU, Ekbom A. The Swedish personal identity number: possibilities and pitfalls in healthcare and medical research. Eur J Epidemiol. 2009;24(11):659-667.

14. Cnattingius S, Ericson A, Gunnarskog J, Källén BA. A quality study of a medical birth registry. Scand J Soc Med. 1990;18(2):143-148.

15. Høgberg U, Larsson N. Early dating by ultrasound and perinatal outcome. A cohort study. Acta Obstet Gynecol Scand. 1997;76(10):907-912.

16. Olesen C, Thrane N, Henriksen TB, Ehrenstein V, Olsen J. Associations between socioeconomic factors and the use of prescription medication during pregnancy: a population-based study among 19,874 Danish women. Eur J Clin Pharmacol. 2006;62(7):547-553.

17. Mahadevan U. Fertility and pregnancy in the patient with inflammatory bowel disease. Gut. 2006;55(8):1198-1206.

18. Uno H, Lohmiller L, Thieme C, et al. Brain damage induced by prenatal exposure to dexamethasone in fetal rhesus macaques. I. Hippocampus. Brain Res Dev Brain Res. 1990;53(2):157-167.

19. Huang WL, Beazley LD, Quinlivan JA, Evans SF, Newnham JP, Dunlop SA. Effect of corticosteroids on brain growth in fetal sheep. Obstet Gynecol. 1999;94(2):213-218.

20. Whitelaw A, Thoresen M. Antenatal steroids and the developing brain. Arch Dis Child Fetal Neonatal Ed. 2000;83(2):F154-F157.

21. Källén BA. Methodological issues in the epidemiological study of the teratogenicity of drugs. Congenit Anom (Kyoto). 2005;45(2):44-51.

22. Mitchell AA. Special considerations in studies of drug-induced birth defects. In: Strom BL, editor. Pharmacoepidemiology. 3rd ed. Chichester (UK): John Wiley \& Sons; 2002:749-763.

23. Pasternak B, Hviid A. Use of acyclovir, valacyclovir, and famciclovir in the first trimester of pregnancy and the risk of birth defects. JAMA. 2010;304(8):859-866.

24. Källén BA, Otterblad Olausson P, Danielsson BR. Is erythromycin therapy teratogenic in humans? Reprod Toxicol. 2005;20(2):209-214.

25. Amann U, Egen-Lappe V, Strunz-Lehner C, Hasford J. Antibiotics in pregnancy: analysis of potential risks and determinants in a large German statutory sickness fund population. Pharmacoepidemiol Drug Saf. 2006;15(5):327-337.

26. Lin HC, Chen IJ, Chen YH, Lee HC, Wu FJ. Maternal schizophrenia and pregnancy outcome: does the use of antipsychotics make a difference? Schizophr Res. 2010;116(1):55-60.

27. Reis M, Källén BA. Maternal use of antipsychotics in early pregnancy and delivery outcome. J Clin Psychopharmacol. 2008;28(3):279-288.
Clinical Epidemiology

\section{Publish your work in this journal}

Clinical Epidemiology is an international, peer-reviewed, open access journal focusing on disease and drug epidemiology, identification of risk factors and screening procedures to develop optimal preventative initiatives and programs. Specific topics include: diagnosis, prognosis, treatment, screening, prevention, risk factor modification, systematic

Submit your manuscript here: http://www.dovepress.com/clinical-epidemiology-journal

\section{Dovepress}

reviews, risk \& safety of medical interventions, epidemiology \& biostatical methods, evaluation of guidelines, translational medicine, health policies \& economic evaluations. The manuscript management system is completely online and includes a very quick and fair peer-review system, which is all easy to use. 